\title{
FORMAÇÃO DE PROFESSOR DE BIOLOGIA E A EDUCAÇÃO AMBIENTAL CRÍTICA: PERSPECTIVAS INVESTIGADAS EM TRABALHOS DE CONCLUSÃO DE CURSO
}

\author{
Camila Salgado Lemke \\ Greici MAIA BEHLING \\ Francele de Abreu Carlan \\ Universidade Federal de Pelotas (UFPel), Pelotas, Rio Grande do Sul, Brasil
}

Resumo: Este estudo buscou compreender as constatações sobre as temáticas "Educação Ambiental" e "Formação de Professores", obtidas por meio da Análise Textual Discursiva dos quatorze resumos de Trabalhos de Conclusão de Curso de egressos do curso de licenciatura em Ciências Biológicas da Universidade Federal de Pelotas. Emergiram desse fenômeno duas categorias denominadas "Problematizando a formação docente em Ciências Biológicas" e "Aportes de uma EA Crítica na formação de professores de Ciências Biológicas". Perante as análises realizadas, notou-se fragilidade na formação crítica e transversal dos docentes. Logo, a EA crítica deve ser uma estratégia para a superação desses obstáculos, tendo em vista a sua importância na tomada de decisões sobre aspectos ambientais e sociais indissociáveis.

Palavras-chave: Formação de Professores. Educação Ambiental Formal. Análise Textual Discursiva. Ciências Biológicas.

\section{CONSIDERAÇÕES INICIAIS}

A formação de professores encontra-se em permanente construção e busca por adequações que possam ser positivas para a melhoria na qualidade profissional dos docentes. No Brasil, a formação de professores foi ancorada, na década de cinquenta, pelo desenvolvimento industrial que impulsionou o desenvolvimento da Ciência e da produção de Tecnologia. Segundo Krasilchik (2000), o processo de industrialização brasileira ocorreu na tentativa de a sociedade superar a dependência de matéria-prima e

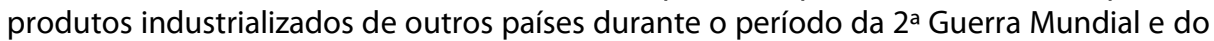
pós-guerra. Isso também foi um passo importante para o desenvolvimento do conhecimento científico em todos os setores da cadeia produtiva, sendo seus reflexos sentidos inclusive no processo de escolarização.

Durante esse período, os temas da biologia constituíam a disciplina de história natural, refletindo grande influência exercida pelo ensino europeu. Na década seguinte, devido à constatação nacional e internacional da importância do ensino de Ciências como fator de desenvolvimento, a situação foi modificada com a promulgação da Lei de 
Diretrizes e Bases da Educação Nacional (LDB) de 1961 (BRASIL, 1961). Segundo Veiga (1978), por influência do processo de industrialização e do desenvolvimentismo iniciados no Brasil, a partir da ditadura, o sistema educacional brasileiro passou a sentir, fortemente, os reflexos da política norte-americana que ofereceu assistência ao Ministério da Educação e Cultura (MEC) brasileiro. Embora tais movimentos tivessem o objetivo de melhorar o ensino das Ciências,

O ensino médio ainda é feito de forma descritiva, com excesso de terminologia sem vinculação com a análise do funcionamento das estruturas, contribuindo para reforçar um ensino teórico, enciclopédico, que estimula a passividade, o exame vestibular que exige conhecimentos fragmentários e irrelevantes (KRASILCHIK, 2008, p. 16).

No momento pós-ditadura, nosso país volta a um processo de redemocratização que traz consigo uma proposta de educação interdisciplinar, contextualizada e humanizadora. De acordo com Leite et al. (2018), com a promulgação da Constituição de 1988, a formação inicial de professores passa por mudanças significativas com vistas a garantir o direito ao desenvolvimento da diversidade cultural e da inclusão em diferentes contextos da escola, permitindo uma educação diferenciada. No entanto, os reflexos na educação básica começaram a ser sentidos a partir da LDB no 9.394 de 1996, quando foram dadas orientações para a criação de Parâmetros Curriculares Nacionais que pudessem orientar a organização curricular, garantindo as especificidades de cada contexto escolar, "incluindo-se, entre outros, o perfil socioeconômico dos estudantes, o direito ao ensino bilíngue e a valorização das particularidades da história e das manifestações culturais regionais" (BRASIL, 1996).

Mais recentemente, a Base Nacional Comum Curricular (BNCC) para o ensino fundamental, - embora destaque a preocupação com a formação integral, crítica e autônoma do sujeito, utilizando o conhecimento científico e tecnológico para compreender os fenômenos e conhecer o mundo, o ambiente, a dinâmica da natureza (BRASIL, 2018) - apresenta um caráter reducionista na apresentação da proposta curricular, contrapondo-se à ideia de formação integral e crítica.

Desse modo, para que os alunos possam desenvolver seu senso crítico, é fundamental que os futuros professores de Ciências e Biologia realizem, ainda durante a formação, a reflexão sobre sua prática, indispensável para pensar possibilidades de desenvolvimento profissional, de forma a contribuir com a aprendizagem dos alunos e promover a cidadania, superando uma imagem do ensino como algo essencialmente simples, para o qual basta um bom conhecimento da matéria, algo de prática e alguns complementos psicopedagógicos (MALUCELLI, 2007).

Contudo, para que esse processo ocorra, além da reflexão sobre a prática é preciso que o corpo docente dos cursos de graduação, que formam professores para atuação na educação básica, ofereçam sustentação teórica e embasamento para tais 
LEMKE, C. S.; BEHLING, G. M.; CARLAN, F. de A.

reflexões, incluindo em suas discussões problemáticas emergentes, dentre as quais destacamos a questão ambiental. De acordo com estudos abordados por Martins e Schnetzler (2018), a EA ainda tem sido trabalhada de forma tradicional e conservadora, sendo necessário um rompimento com o modelo conservador, garantindo o fortalecimento da formação de professores a partir do desenvolvimento de uma EA crítica e emancipatória. Logo, é fundamental que, diante das problemáticas emergentes, a universidade busque sua reinvenção.

Nesse contexto, além da universidade precisar assumir uma nova postura, em tempos de crise ambiental e de crise do conhecimento científico, será necessário que os cursos que formam professores repensem suas estruturas curriculares, sendo convocados a assumirem um posicionamento crítico-reflexivo que resulte na transformação dos paradigmas científicos tradicionais, promovendo novos conhecimentos e a integração dos saberes com a participação da sociedade (MORALES, 2007).

A crise emergente ambiental já é estudada há bastante tempo e a importância da Educação Ambiental não é novidade. A educação representa um pilar fundamental, juntamente aos meios políticos, econômicos, legais, científicos, éticos e técnicos, para o combate à problemática ambiental, pois tem respondido positivamente à formação dos sujeitos (LIMA, 2002). Para isso, iniciar pelo caminho da formação docente é fundamental, a partir de uma premissa de educação que consolide a construção de um saber ambiental.

Nesse aspecto, destacamos a Educação Ambiental (EA) como estratégia para a articulação de um sistema capaz de unificar os conhecimentos acerca do tema. A relação da universidade com as questões associadas ao meio ambiente foi muito difícil, pois a dualidade e a departamentalização tendem a valorizar as especificidades e deixar de lado as posições pluralistas (BURSZTYN, 2001). Logo, a temática "EA" acaba sendo uma das mais prejudicadas, uma vez que necessita ser trabalhada dentro de uma perspectiva transversal, e as universidades ainda se organizam dentro de uma lógica fragmentada, existindo, portanto, resistência e tensões quanto ao assunto.

Embora a universidade "não pareça preparada para defrontar os desafios, tanto mais que esses apontam para transformações profundas e não para simples reformas parcelares" (SANTOS, 2001, p. 187), precisamos promover ações que visem a compreensão da temática ambiental, buscando alternativas reais para a prática docente dos licenciandos, incentivando a posição crítico-reflexiva e em torno de uma percepção que extrapole a condução de conceitos e atividades ecológicas.

Nesse sentido, pensando que os principais sujeitos atuantes na promoção da EA dentro do espaço da escola são, muitas vezes, os professores de Ciências e Biologia, o objetivo deste trabalho foi analisar o que revelam os quatorze Trabalhos de Conclusão de Curso produzidos no período de 2005 a 2018 por licenciandos do curso de Ciências Biológicas da UFPel sobre as temáticas "Educação Ambiental" e Formação de Professores".

\section{MetOdOLOGIA}


Para a realização deste estudo consideramos a pesquisa qualitativa a abordagem mais adequada. Assim, partiu-se da seguinte questão de pesquisa: "o que revelam os Trabalhos de Conclusão de Curso (TCC) de alunos do curso de licenciatura de Ciências Biológicas da Universidade Federal de Pelotas (UFPel) cuja temática está relacionada com a EA e formação de professores?". Do total de duzentos e setenta e oito TCCs registrados no sistema de bibliotecas da UFPel no período de 2005 a 2018, foram selecionados aqueles cujos resumos citavam em suas palavras-chave os termos relacionados à EA e à formação de professores ${ }^{1}$, totalizando quatorze resumos, ou seja, $5 \%$ dos registros disponíveis no sistema de bibliotecas.

Esses resumos constituíram o corpus e foram analisados por meio da Análise Textual Discursiva (ATD) - (SOUZA; GALIAZZI, 2018). Inicialmente, o material foi reunido, sendo realizada uma leitura meticulosa. Então, o corpus foi organizado em uma planilha eletrônica e dividido em unidades de significado, o chamado processo de unitarização, ou seja, a separação do texto a partir de sentidos atribuídos pelo interlocutor. Após essa fase, ocorreu a categorização, que é a articulação entre unidades de significado semelhantes, reorganizando o texto. Assim, a análise se desloca do empírico para a abstração teórica, resultando no metatexto (MORAES; GALIAZZI, 2006), que combina descrição com interpretação e mostra-se como um fenômeno para a compreensão do modo como os alunos relacionam-se com a EA e a formação de professores durante a graduação.

Emergiram, deste fenômeno, duas categorias abertas denominadas "Problematizando a formação docente em Ciências Biológicas" e "Aportes de uma EA Crítica na formação de professores de Ciências Biológicas", as quais serão discutidas a seguir.

\section{RESULTADOS E DISCUSSÃO}

Após a análise do corpus, por meio de ATD, chegamos a duas categorias: "Problematizando a formação docente em Ciências Biológicas", que emergiu das análises realizadas pelos licenciandos em seus TCCs a respeito do contexto de formação de professores de Ciências Biológicas da UFPel, buscando compreender as principais fragilidades como forma de viabilizar possibilidades de superação, a partir da perspectiva dos licenciandos, e "Aportes de uma EA crítica na formação de professores de Ciências Biológicas", que surgiu a partir das constatações observadas nos quatorze TCCs analisados. A partir disso, propomos a inclusão da EA crítica como potencialidade para superação da problemática trazida nos trabalhos, como instrumento para superar tais fragilidades, pois a discussão sobre a EA, durante a graduação, pode proporcionar uma contextualização essencial para a compreensão das problemáticas emergentes na sociedade moderna.

PROBLEMATIZANDO A FORMAÇÃo DOCENTE EM CIÊNCIAS BIOLÓGICAS 
LEMKE, C. S.; BEHLING, G. M.; CARLAN, F. de A.

Nessa categoria serão destacadas e discutidas as principais fragilidades apontadas pelos licenciados em seus TCCs quanto à formação docente, bem como as algumas reflexões acerca das possibilidades de superá-las.

Os cursos voltados à formação de professores devem construir com os futuros docentes a compreensão de que o processo reflexivo auxilia na (re)construção e (re)avaliação de concepções, anteriormente formuladas, e na busca pela identidade profissional. Nesse contexto, pode-se inferir que o processo reflexivo deve partir dos saberes docentes acumulados e adquiridos pelo professor, e sobre isso Tardif (2014, p. 33) afirma que:

[...] o saber docente se compõe, na verdade, de vários saberes provenientes de diferentes fontes. Esses saberes são os saberes disciplinares, curriculares, profissionais (incluindo os das ciências da educação e da pedagogia) e experienciais que embora ocupem uma posição estratégica entre os saberes sociais, o corpo docente é desvalorizado em relação aos saberes que possui e transmite (TARDIF, 2014, p. 33).

A partir de tais discussões, compreende-se que os docentes que atuam em cursos de licenciatura apresentam a importante tarefa de auxiliar seus discentes na construção dos saberes necessários para a constituição do futuro professor. Apesar de compreendermos, como afirma Nóvoa (1992, p. 13), que "a formação é construída mediante a acumulação de cursos, conhecimentos ou técnicas, mas por meio da reflexão crítica sobre as práticas e de (re)construção permanente da identidade", é preciso considerar a importância de uma formação acadêmica de qualidade. Dessa maneira, nos resumos dos TCCs analisados na presente pesquisa, constatou-se que os acadêmicos julgaram fundamental a existência de uma identificação do docente do ensino superior, que ministra aula para a licenciatura, com a docência como forma de auxiliar na construção da identidade dos licenciandos. Ainda destacaram a importância da superação do modelo de aula no ensino superior baseado na mera transmissão de conteúdo e do investimento em uma prática pedagógica pautada na observação das reais necessidades dos alunos, despertando a motivação, como forma de auxiliar no desenvolvimento de uma prática crítico-reflexiva pelos futuros professores.

A prática crítico-reflexiva está, muitas vezes, associada à investigação sobre o fazer docente, pois confere aos professores a habilidade em estabelecer o que está ou não funcionando no processo de aprendizagem, o que está ou não agregando significados para o aluno e se aquela prática, por sua vez, contribui para a formação crítico-reflexiva daquele aluno, conferindo, assim, novas oportunidades para o seu desenvolvimento e para a sua compreensão do mundo.

Uma prática docente crítico-reflexiva envolve o movimento dinâmico, dialético, entre o fazer e o pensar sobre o fazer (FREIRE, 2001). Assim, ela fornece oportunidades recursivas que permitem rever acontecimentos e práticas, de forma a desenvolver, nos alunos, o senso crítico, pois, como nos diz Freire (2001): 


\begin{abstract}
Ensinar não é transferir conteúdo a ninguém, assim como aprender não é memorizar o perfil do conteúdo transferido no discurso do professor. Ensinar e aprender tem que ver com o esforço metodicamente crítico do professor de desvelar a compreensão de algo e com o empenho crítico do aluno de ir entrando como sujeito em aprendizagem, no processo de desvelamento que o professor ou professora deve deflagrar. Isso não tem nada que ver com a transferência de conteúdo e fala da dificuldade, mas, ao mesmo tempo, da boniteza da docência e da discência (FREIRE, 2005, p. 118).
\end{abstract}

Dessa forma, a postura crítico-reflexiva não requer apenas o saber fazer, mas o explicar de forma consciente a sua prática e as decisões tomadas sobre ela, percebendo se essas decisões são as melhores para favorecer a aprendizagem do seu aluno.

Foram encontrados ainda apontamentos sobre a ausência de uma postura crítico-reflexiva como uma fragilidade na formação, refletindo na insatisfação de muitos licenciados com a sua preparação profissional. Esse movimento de reflexão conduziu os autores dos TCCs ao desenvolvimento do pensamento sobre as suas práticas educativas. Os licenciandos consideraram que a construção da criticidade, em diversas disciplinas, foi promovida de maneira pontual, estimulando o pensamento sobre a funcionalidade de determinadas metodologias utilizadas na prática, mas não no contexto da construção da cidadania através destas práticas.

Em contraponto, como potencialidade, foi destacado o estímulo à reflexão sobre os pilares da sociedade contemporânea e sobre o papel do impacto da falta de políticas públicas e dos baixos investimentos na desvalorização da educação e no desencantamento pelo espaço da escola.

Logo, foi possível perceber pelos pontos destacados nos resumos analisados que, para os licenciandos, a universidade se caracteriza como fundamental na construção da identidade docente e no estímulo ao exercício crítico-reflexivo, embora não atribuam ao curso de licenciatura em Ciências Biológicas total responsabilidade pelo estabelecimento da sua consciência crítica, por entenderem que cabe ao indivíduo buscar os melhores meios para se desenvolver como sujeito ativo do seu processo de formação.

Outra fragilidade destacada nos resumos analisados foi com relação às diferentes concepções epistemológicas identificadas entre os DES, como um ponto responsável pelo incentivo ou não ao pensamento crítico. Tais concepções epistemológicas, as quais originam as três perspectivas pedagógicas estruturantes das teorias da aprendizagem foram identificadas pelos autores dos TCCs em seus professores do curso de licenciatura em Ciências Biológicas, entre elas: a empirista, a apriorista e a interacionista.

A perspectiva empirista determina que o conhecimento sobre o mundo vem apenas da experiência sensorial, na qual "o aluno seria incapaz de aprender sem a 
presença de um professor, estabelecendo uma relação de passividade do aluno para com o professor, detentor total dos estímulos que culminarão na aprendizagem" (FREIRE, 1987; BECKER, 1998; RIZZON, 2009). Já para a perspectiva pedagógica apriorista, "o conhecimento é latente ao indivíduo, pois ele já carrega consigo as nuances necessárias para assimilá-lo". O ambiente, neste caso, seria secundário, e atuaria no preenchimento de formas já desenvolvidas com o conteúdo (BECKER, 1992). O interacionismo, por sua vez, determina ser fundamental que o indivíduo se insira em determinado meio cultural para que aconteçam mudanças no seu desenvolvimento (VYGOTSKI, 1982).

Vale destacar que, na estruturação do Projeto Pedagógico de Curso (PPC) nas licenciaturas, é necessário que o currículo contemple a definição dos objetivos do ensino, selecionando conteúdos e organizando situações de aprendizagem, principalmente para uma educação em Ciências que considere as questões sociais e culturais envolvidas no desenvolvimento científico, isto é, em consonância com uma construção epistemológica coerente com a criticidade.

Por essa razão, salienta-se a necessidade de preocupação com uma base teórica que possa dar suporte à prática do educador no seu fazer pedagógico cotidiano (HERNÁNDEZ, 1998), pois a sua ausência pode causar a mistura entre concepções epistemológicas distintas. Segundo Laranjeira (2000), a lacuna no cotidiano pedagógico, tanto na ausência de um contexto de reflexão epistemológica como na ausência de um contexto de exercício cognitivo de construção de conceitos e aplicação de princípios, podem levar o professor a assumir noções do senso comum.

Outra potencialidade destacada, pelos licenciandos, nos TCCs foi o desenvolvimento do pensamento crítico-reflexivo sobre o fazer docente na graduação durante o estabelecimento de tarefas, como a escrita em diário de bordo, a observação e o registro das aulas na educação básica, o desenvolvimento dos planejamentos de aula e, especialmente, no momento da escrita dos relatórios finais dos estágios obrigatórios da licenciatura. É nesse processo que julgaram ter iniciado a construção da postura docente e o despertar da identidade como futuro(a) professor(a). Também foi encontrado nos TCCs um destaque para os cinco estágios supervisionados obrigatórios como os responsáveis pelo início do processo de construção do pensamento críticoreflexivo.

No entanto, nesta análise dos dados, encontrou-se que, durante a formação inicial dos acadêmicos responsáveis pelos TCCs analisados, os instrumentos que auxiliaram na promoção da reflexão e, consequentemente, no exercício crítico-reflexivo, estiveram sob a responsabilidade de algumas disciplinas, não sendo utilizados com o aprofundamento necessário pela maioria dos professores. Um dos fatores que justifica a construção desses instrumentos reflexivos, exclusivamente por disciplinas pedagógicas, possivelmente está relacionado com a formação dos professores das demais áreas do conhecimento, como, por exemplo, em Zoologia, em Botânica, em Genética, entre outras, não apresentar formação pedagógica, portanto, estando, distantes da realidade da educação básica, além de apresentarem pouco diálogo com a área pedagógica. 
Nesse contexto, é importante mencionar que a preparação dos docentes para o exercício do magistério no ensino superior ocorre em nível de pós-graduação, prioritariamente, em programas de pós-graduação (mestrado e doutorado), não havendo, necessariamente, preocupação com a formação pedagógica:

\begin{abstract}
Quando existe alguma formação para a docência neste grau de ensino, esta se encontra circunscrita a uma disciplina de Metodologia do Ensino Superior, nos momentos da pós-graduação, com carga horária média de 60 horas. Situa-se nesta disciplina, muitas vezes, as referências e orientações para o professor universitário atuar em sala de aula. Não há uma exigência de conhecimentos de base para o magistério e nem uma formação sistemática propiciadora da construção de uma identidade profissional para a docência (ANASTASIOU, 2005, p. 04).
\end{abstract}

A formação de professores, muitas vezes, é realizada de forma distante das discussões sociais, culturais e políticas que permeiam o espaço da escola e que precisam ser incorporadas aos cursos que formam professores. Muitas vezes, a bagagem que o futuro professor obtém no ensino superior não condiz com a realidade encontrada na maioria das escolas brasileiras. Dessa forma, a aprendizagem do licenciando passa a ser pouco significativa quando a formação ocorre desvinculada das diferentes realidades existentes no espaço escolar.

De acordo com Santos (2001), a universidade foi sempre acusada de raramente ter mobilizado os conhecimentos acumulados a favor dos problemas sociais. No entanto, esse contexto está melhorando ao longo dos anos, mas precisa de mais incentivos públicos, bem como investimentos e professores pesquisadores sensíveis às diversas realidades sociais e suas problemáticas emergentes. Assim, as universidades poderão firmar um posicionamento crítico-reflexivo, construindo um novo entendimento que induza à transformação dos paradigmas científicos tradicionais, promovendo novos tipos de conhecimentos, buscando a integração com a sociedade (MORALES, 2007).

Nesse contexto, entendemos que uma das formas de superação das problemáticas apontadas, nesta categoria, relaciona-se à atualização dos cursos que formam professores, exigindo dos docentes do ensino superior constante busca pelo seu aprendizado, visando à integração dos saberes sociais, ambientais e políticos, superando a ideia de conhecimento como algo estático e fragmentado para ser reconhecido enquanto um processo dinâmico.

APORTES DE UMA EDUCAÇÃO AMBIENTAL CRÍTICA NA FORMAÇÃO DE PROFESSORES DE BIOLOGIA 
LEMKE, C. S.; BEHLING, G. M.; CARLAN, F. de A.

Partindo do pressuposto que as duas principais fragilidades apontadas nos TCCs pelos licenciandos foram a criticidade, que não perpassa todas as disciplinas do curso, e a dissonância entre as correntes epistemológicas e perspectivas pedagógicas dentro da graduação, propomos, nesta categoria, a inclusão da EA crítica como potencialidade de superação da problemática trazida nos trabalhos analisados. Por isso, a Educação Ambiental surge como estratégia para tornar possível pensar a formação docente a partir de uma perspectiva da epistemologia ambiental de Leff (2002).

Um dos aspectos apontados como deficiente na formação encaixa-se na perspectiva do trabalho com questões transversais, destacando aqui, especificamente, a EA. Não há legitimidade em solicitar de um docente que trabalhe determinados conceitos e habilidades necessários à construção de uma crítica socioambiental se ele não recebeu a adequada formação para tal. Assim, para que o debate socioambiental seja praticado, é necessário que a realidade das comunidades seja considerada, buscando a contextualização de seus problemas e suas percepções. Essa questão está, intrinsecamente, relacionada à vertente pedagógica da EA adotada no processo, por isso, é fundamental explicar qual o ponto de partida.

Layrargues e Lima (2014) apontam que existem três macrotendências políticopedagógicas da EA atualmente: a conservacionista, a pragmática e a crítica. A conservacionista constitui um viés precursor da EA caracterizado como puramente ecológico e apolítico. Já a tendência pragmática vê a Educação Ambiental como um meio para atingir o desenvolvimento sustentável e, em sua maioria, se detém nos trabalhos quanto à geração crescente de resíduos sólidos e soluções tecnológicas para os problemas ambientais.

Embora sejam duas macrotendências bastante presentes na prática docente no ensino superior, é necessário abandonar tanto a lógica conservacionista, que adota uma perspectiva com viés ecológico, quanto a questão ambiental, que perde de vista as dimensões sociais, políticas e culturais indissociáveis, assim como a pragmática, que muito se propõe a agir conforme a produção e apenas focar nos problemas pontuais, não contemplando a complexidade ambiental e social que existe.

Como alternativa a essas tendências, surgiu então uma terceira macrotendência, denominada EA crítica que, segundo Lima (2009), foi promovida através de correntes ambientalistas e democráticas a partir de 1980, com a aproximação entre os setores dos movimentos sociais. O principal ponto a ser destacado é a problematização e a politização das questões ambientais, ampliando a discussão ambiental para tendências sociais que não podem ser separadas do meio ambiente. $\mathrm{A}$ EA crítica entende as relações complexas entre as questões ambientais emergentes e as diferentes faces de poder e dominação, sendo esse reconhecimento gerador de um grande conhecimento transformador (LAYRARGUES; LIMA, 2014).

Dessa forma, é necessário que os professores se apropriem de uma percepção que "ultrapasse a manipulação de conteúdos ecológicos e que, também, supere a simples aplicação de técnicas ecológicas" (GUIMARÃES; INFORSATO, 2012). A transposição dessa barreira ainda é um desafio em muitas escolas do país, pois boa parte da formação desses professores pode ter sido deficitária no campo da EA. 
Além disso, os licenciandos de áreas que não possuem correlação direta com as Ciências da Natureza sofrem para sistematizar a relação das temáticas que devem ser trabalhados pela EA, recaindo, geralmente, aos licenciados em Ciências Biológicas, a responsabilidade em "assumir" a EA na escola.

No campo de atuação docente, a EA promove a discussão sobre as questões globais, suas causas e consequências a partir de um contexto social e histórico. Como a EA crítica é um campo do conhecimento integrado com as questões ambientais, sociais e econômicas, ela é um dos principais agregadores de tais aspectos na formação desses futuros professores.

Para isso, é necessário que as instituições de ensino superior tenham uma gestão integrada com a realidade educacional da comunidade externa. A integração entre a universidade e a sociedade pode ocorrer de diversas maneiras, sendo necessário que articulem pesquisa e/ou extensão e reverberem no ensino. Quando ocorridas as atividades de extensão, por exemplo, geralmente são contempladas a multidisciplinaridade e a articulação de saberes científicos e não científicos (SCHOMMER, 2005). Entretanto, no campo do ensino, articular experiências interdisciplinares, tanto em sala de aula quanto em atividades de pesquisa ou de extensão, possibilita o trabalho da grade curricular em perspectiva ampliada, a fim de que o desenvolvimento educacional acompanhe o avanço da ciência e oportunize a formação de docentes críticos quanto à constituição da cidadania (PROGRAMA ACC, 2003).

Segundo Leff (2002), o que a problemática ambiental exerce na Instituição de Ensino Superior (IES) "transcende a criação de um espaço formado pela integração das disciplinas tradicionais" porque ultrapassa a mera atualização dos currículos universitários. Para o autor, o saber ambiental constrói-se "por um conjunto de processos de natureza diferente, cuja diversidade de ordens ontológicas, de racionalidades, de interesses e de sentidos não pode estar contida num modelo global, por mais holístico e aberto que este seja" (LEFF, 2002, p. 164).

Nesse contexto, a EA crítica está relacionada a uma epistemologia ecológica (LEFF, 2003), pois pode contribuir na formação dos docentes de Biologia ao compreender a realidade como materialidade socioambiental que envolve os indivíduos nas mais variadas facetas da vida em sociedade. Para Morin (2001), a universidade conserva, memoriza, integra, ritualiza uma herança de saberes, valores, ideias etc. Ela regenera essa herança ao examiná-la e atualizá-la, gerando, assim, saberes, ideias e valores que passam a fazer parte dessa herança. Não há, ainda, uma herança relacionada às questões ambientais.

Uma consequência dessa situação, conforme indicam os licenciandos em seus TCCs, é que a universidade não os preparou para a interdisciplinaridade, erro que ainda hoje persiste nos cursos de licenciatura (BIZERRIL; FARIA, 2001), o que leva o futuro docente a não conseguir agir no contexto da escola e a não se sentir muito confiante para estabelecer um projeto de EA. Além disso, foi mencionado nos trabalhos que 
muitos professores de disciplinas específicas não se propõem a atuar em projetos transversais, mantendo sempre a sua individualidade no trabalho.

Entretanto, a escola é um espaço frutífero para o estabelecimento de relações e conexões que possibilitem aos estudantes a compreensão da cidadania e da sua responsabilidade com o meio ambiente. Logo, a educação formal continua sendo um espaço importante para o desenvolvimento de valores e atitudes comprometidas com a sustentabilidade ecológica e social (LIMA, 2004). Segundo Leff (2001), a EA deveria articular o educando ao conhecimento, suas formas de produção, a descobrir os sentidos e sabores do saber para que, assim, desenvolva mais que o pensamento crítico, um pensamento crítico-reflexivo e prospectivo capaz de combater condutas utilitaristas tão presentes na sociedade globalizada moderna.

Questões básicas relacionadas com o desenvolvimento e o meio ambiente, tais como população, saúde, paz, direitos humanos, democracia, fome, degradação da flora e da fauna devem ser abordadas (CASCINO, 2003) nas ações do professor, que possui caráter decisivo sobre a formação das ideias dos seus alunos, desde seu contexto social, pertencimento, percepção e compreensão das questões ambientais. Sendo assim, a EA crítica contribui no processo de "construção de uma sociedade pautada por novos patamares civilizacionais e societários distintos dos atuais, em que a sustentabilidade da vida e a ética ecológica sejam seu cerne" (LOUREIRO, 2002).

Nesse contexto, a EA pode funcionar como uma espécie de tradutor entre os saberes construídos pelas universidades e os saberes populares, bem como pela integração destes à realidade do ensino superior. Esse diálogo de saberes no âmbito educacional é o encontro do conhecimento científico, sistematizado, comprovado e aprendido na escola com o conhecimento ou saber popular adquirido por meio da experiência de vida, que expressa sentidos e identidades. O diálogo pressupõe a troca entre sujeitos em relação horizontal, na qual não existe melhor ou pior, pois ambos possuem conhecimentos construídos científica ou socialmente (ANDRADE, 2010).

A complexidade ambiental contemporânea, segundo definição de Leff (2001), é caracterizada como a expressão do reconhecimento da crise civilizatória atual, resultado da "projeção de um pensamento e ação complexos orientados no sentido de reconstrução do mundo sob novas bases na relação sociedade - natureza". Dessa maneira, no processo para uma sociedade mais sustentável é imprescindível que se invista na EA, visto que a educação é o principal fator para a mudança de paradigmas.

\section{CONSIDERAÇÕES FINAIS}

É notável que dentre os egressos do curso de Ciências Biológicas da Universidade Federal de Pelotas existe a preocupação de como sua formação docente influenciará na sua atuação em sala de aula. Assim, são levantadas fragilidades encontradas nessa formação, como a carência no desenvolvimento da criticidade na maioria das disciplinas do curso; a dissonância entre as correntes epistemológicas e perspectivas pedagógicas dentro da graduação e a deficiência em torno de uma perspectiva transversal. Portanto, para que se busque atender às demandas da 
sociedade, formando cidadãos críticos, pensantes e atuantes é necessário que se invista na EA crítica na formação de professores. Porém, esse é um desafio contemporâneo, pois exige superar a compartimentalização dos saberes em direção ao pensar as realidades de maneira, cada vez mais, multidisciplinar e transversal.

Artigo recebido em: 20/08/2020

Aprovado para publicação em: 30/12/2020

\section{BIOLOGY TEACHER TRAINING AND CRITICAL ENVIRONMENTAL EDUCATION: PERSPECTIVES INVESTIGATED IN COURSE COMPLETION WORKS}

ABSTRACT: This study sought to understand how graduates of Biological Sciences at Federal University of Pelotas are related to Environmental Education in their training. For this purpose, through Discursive Textual Analysis, fourteen abstracts of Course Conclusion Papers from Biological Sciences at UFPel were analyzed. Two categories emerged from this phenomenon: "Problematizing teacher education in Biological Sciences" and "Support for a Critical EE in the training of Biological Sciences teachers". There was a weakness in the critical and transversal training of teachers. Therefore, critical EE should be a strategy for overcoming these obstacles, in view of its importance in making decisions about inseparable environmental and social aspects.

KEYWORDS: Teacher Training. Formal Environmental Education. Discursive Textual Analysis; Biological Sciences.

FORMACIÓN DE PROFESORES DE BIOLOGÍA Y EDUCACIÓN AMBIENTAL CRÍTICA: PERSPECTIVAS INVESTIGADAS EN TRABAJOS DE FINALIZACIÓN DE CURSO

RESUMEN: Este estudio buscó comprender cómo los egresados de Ciencias Biológicas de la Universidad Federal de Pelotas se relacionan con la Educación Ambiental en su formación. A través del Análisis Textual Discursivo, se analizaron catorce resúmenes de Trabajos de Conclusión del Curso de la carrera de Licenciatura en Ciencias Biológicas de la UFPel. De este fenómeno surgieron dos categorías: "Problematización de la formación del profesorado en Ciencias Biológicas" y "Apoyo a una EA Crítica en la formación de profesores de Ciencias Biológicas". A la vista de los análisis realizados, se evidencia una debilidad en la formación crítica y transversal de los docentes. Creyó que la EA crítica debe ser una estrategia para superar estos obstáculos, dada su importancia en la toma de decisiones sobre aspectos ambientales y sociales inseparables.

PALABRAS CLAVE: Formación Docente. Educación Ambiental Formal. Análisis Textual Discursivo. Ciencias Biologicas. 


\section{NotA}

1 - Atualização de professores; cidadania; educação; EA; ensino de ciências; ensino e aprendizagem; ensino médio; ensino público; ensino superior; formação inicial e continuada de professores; prática pedagógica; problemática ambiental; sustentabilidade.

\section{REFERÊNCIAS BIBLIOGRÁFICAS}

ANASTASIOU, L G. C. Construindo a docência no ensino superior: relação entre saberes pedagógicos e saberes científicos. In: FERENC, A. V. F. MIZUKAMI, M. da G. N. Formação de professores, docência universitária e o aprender a ensinar. Formação docente para o ensino superior, 2005.

ANDRADE, M. R. Notas para discussão sobre o diálogo de saberes: experiências inovadoras no ensino de ATER. SEMINÁRIO NACIONAL DE ENSINO EM EXTENSÃO RURAL, v. 2, 2010.

BECKER, F. A epistemologia do professor: o cotidiano da escola. 7 ed. Petrópolis: Vozes, 1998.

BECKER, F. O que é construtivismo. Revista de Educação AEC, Brasília, v. 21. n. 83, p.715, abr./jun. 1992.

BIZERRIL, M.; FARIA, D. Percepção de professores sobre a educação ambiental no ensino fundamental. In: Revista Brasileira de Estudos Pedagógicos. Brasília, v. 82, n. 200/201/202, p. 57-69, jan./dez. 2001. Disponível em: $<$ http://rbep.inep.gov.br/ojs3/index.php/rbep/article/view/1349>. Acesso em: 10 ago. 2020.

BRASIL. Base Nacional Comum Curricular (BNCC): Educação é a Base. Brasília, MEC/CONSED/UNDIME, 2018.2 Disponível em: $<\underline{\text { http://basenacionalcomum.mec.gov.br/images/BNCC_El_EF_110518_versaofinal_site. }}$ pdf >. Acesso em: 10 ago. 2020.

BRASIL. Lei no 9.394, de 20 de dezembro de 1996. Estabelece as diretrizes e bases da educação nacional. Diário Oficial da União, v. 134, n. 248, 1996.

BRASIL, Lei no 4.024, de 20 de dezembro de 1961. Estabelece as diretrizes e bases da educação nacional. Diário Oficial da República Federativa do Brasil, Brasília, DF, 23 
dez. 1961. Disponível em: <https://www2.camara.leg.br/legin/fed/lei/1960-1969/lei4024-20-dezembro-1961-353722-promulgacaodevetos-47770-pl.html>. Acesso em: 10 ago. 2020.

BURSZTYN, M. (org.) Ciência, Ética e Sustentabilidade - Desafios ao novo século. São Paulo: Cortez; Brasília: UNESCO, 2001.

CASCINO, F. Educação ambiental: princípios, história, formação de professores. $3^{a}$ edição. São Paulo: Editora Senac, 2003.

FREIRE, P. Pedagogia da Autonomia: saberes necessários à prática educativa. São Paulo: Paz e Terra, 2001.

FREIRE, P. Pedagogia do oprimido. 17 ed. Rio de Janeiro: Paz e Terra, 1987.

GUIMARAES, S.; INFORSATO, E. A percepção do professor de Biologia e a sua formação: a Educação Ambiental em questão. Ciênc. educ. Bauru , v. 18, n. 3, p. 737-754, 2012. Disponível em: <https://www.scielo.br/scielo.php?pid=S151673132012000300016\&script=sci_arttext>. Acesso em: 20 Mai. 2020.

HERNANDEZ, F. A importância de saber como os docentes aprendem. Pátio Revista Pedagógica. Porto Alegre: Artes Médicas Sul, fev./abr. 1998.

KRASILCHIK, M. Prática de Ensino de Biologia. São Paulo: Universidade de São Paulo, 4a ed., rev. e ampl., $2^{\text {a }}$ reimpr., 2008.

KRASILCHIK, M. Reformas e realidade: o caso do ensino das ciências. São Paulo Perspec., São Paulo , v. 14, n. 1, p. 85-93, Mar. 2000 . Disponível em: $<$ http://www.scielo.br/scielo.php?pid=S010288392000000100010\&script=sci_arttext\&t| ng=pt>. Acesso em: 20 Mai. 2020.

LARANJEIRA, M. I.; Quem ensina, como aprende. In: Da arte de aprender ao ofício de ensinar: relato, em reflexão, de uma trajetória. São Paulo: EDUSC, 2000. p. 103-114.

LAYRARGUES, P.P.; LIMA, G.C. As macrotendências político-pedagógicas da Educação Ambiental brasileira. Ambiente \& Sociedade, v. 17, n. 1, p. 23-40, mar. 2014. Disponível em: < https://www.scielo.br/pdf/asoc/v17n1/v17n1a03.pdf $>$. Acesso em: 10 ago. 2020.

LEFF, E. (org.). A Complexidade Ambiental; Tradução de Eliete Wolff. São Paulo: Cortez, 2003. 
LEMKE, C. S.; BEHLING, G. M.; CARLAN, F. de A.

LEFF, E. Epistemologia Ambiental. 3 ed. São Paulo: Cortez, 2002.

LEFF, E. Epistemologia ambiental. São Paulo: Cortez, 2001a.

LEITE, E. A. P. ; RIBEIRO, E. S. da; LEITE, K.G.; ULIANA, M. R. Alguns Desafios e Demandas da Formação Inicial de Professores na Contemporaneidade. Educação \& Sociedade, v. 39, n. 144, Campinas/SP, jul/set, 2018.

LIMA, G. C. "Crise ambiental, educação e cidadania". In: LAYRARGUES, P. P.; Castro, R. S; LOUREIRO, C. F. B. (orgs) Educação ambiental: repensando o espaço da cidadania., São Paulo: Cortez, 2002.

LIMA, G.C. Educação Ambiental crítica: do socioambientalismo às sociedades sustentáveis. Educação e Pesquisa, v.35, n.1, p. 145-163, jan./abr. 2009. Disponível em <https://www.scielo.br/pdf/ep/v35n1/a10v35n1.pdf>. Acesso em: 10 ago. 2020.

LIMA, W. Aprendizagem e classificação social: um desafio aos conceitos. In: Forum crítico da educação: revista do ISEP. Instituto Superior de Estudos Pedagógicas, v. 3, n. 1, out. 2004.

LOUREIRO, J. D. J. P. Educação Ambiental e movimentos sociais na construção da cidadania ecológica e planetária. In: LOUREIRO, C. F. B.; LAYRARGUES, P. P.; CASTRO, R. S. de. Educação Ambiental: repensando o espaço da cidadania. São Paulo: Cortez, 2002.

MALUCELLI, V. M. B. Formação dos professores de Ciências e Biologia: reflexões sobre os conhecimentos necessários a uma prática de qualidade. Estudos de Biologia, v. 29, n. 66, 2007.

MARTINS, J. P. A; SCHNETZLER, R. P. Formação de professores em educação ambiental crítica centrada na investigação-ação e na parceria colaborativa. Ciência \& Educação (Bauru), v. 24, n. 3, p. 581-598, 2018.

MORAES, R; GALIAZZI, M. C. Análise textual discursiva: processo reconstrutivo de múltiplas faces. Ciênc. educ. (Bauru), Bauru, v. 12, n. 1, p. 117-128, 2006 . Disponível em: https://cutt.ly/VjjhmDR. Acesso em: 05 jan. 2021.

MORALES, A. G. M. O processo de formação em educação ambiental no ensino superior: trajetória dos cursos de especialização. Revista Eletrônica do Mestrado em Educação Ambiental, Rio Grande, v. 18, jan./jun. 2007. Disponível em: <https://periodicos.furg.br/remea/article/view/3554/2118>. Acesso em: 10 ago. 2020. MORIN, E. A cabeça bem-feita. Rio de Janeiro: Bertrand Brasil, 2001. 
NÓVOA, A. Os professores e a sua formação. Lisboa: Dom Quixote, 1992. ISBN 972-201008-5. Disponível em: http://hdl.handle.net/10451/4758. Acesso em: 10 ago. 2020.

PROGRAMA ATIVIDADE CURRICULAR EM COMUNIDADE - ACC. Ano letivo de 2003. Propostas apreciadas e aprovadas pelas Câmaras de Extensão e de Ensino de Graduação do Conselho de Ensino, Pesquisa e Extensão da Universidade Federal da Bahia. Salvador, abril de 2003.

RIZZON, G. Investigando Piaget: a epistemologia genética e o apriorismo. 2009. Dissertação (Mestrado em Educação) - Universidade de Caxias do Sul, Caxias do Sul, 2009.

SANTOS, B. S. Pela mão de Alice: o social e o político na pós-modernidade. São Paulo: Cortez, 2001.

SCHOMMER, P. C. Comunidades de prática e articulação de saberes na relação entre universidade e sociedade. 2005. Tese (Doutorado em Administração de Empresas) Escola de Administração de Empresas, São Paulo. 2005.

SOUSA, R; GALIAZZI, M. C. O jogo da compreensão na análise textual discursiva em pesquisas na educação em ciências: revisitando quebra-cabeças e mosaicos. Ciênc. educ. (Bauru), Bauru, v. 24, n. 3, p. 799-814, 2018. Disponível em: $<$ http://www.scielo.br/scielo.php?script=sci_arttext\&pid=S1516-

73132018000300799\&lng=en\&nrm=iso >. Acesso em: 05 jan. 2021.

TARDIF, M. Saberes docentes e formação profissional. 17a ed. Petrópolis: Vozes, 2014. VEIGA, I. P. A. Didática: Uma retrospectiva histórica. In: Repensando a Didática. Campinas: Papirus, 1978.

VYGOTSKY, L. S. Obras Escogidas: problemas de psicologia geral. Gráficas Rogar. Fuenlabrada. Madrid, 1982. p. 387.

Camila Salgado Lemke: Técnica em Meio Ambiente pelo Instituto Federal de Educação, Ciência e Tecnologia Sul-Rio-Grandense Campus Pelotas Visconde da GraçaIFSul/CaVG. Graduanda no Curso de Ciências Biológicas na modalidade Licenciatura, pela Universidade Federal de Pelotas-UFPel. Atualmente é bolsista no Projeto de Ensino: Recursos didáticos para o ensino de Ciências e Biologia, o qual atua na construção e aplicação de metodologias, estratégias e recursos didáticos inovadores e que promovam 0 protagonismo docente.

Orcid: https://orcid.org/0000-0003-2759-9407 
LEMKE, C. S.; BEHLING, G. M.; CARLAN, F. de A.

E-mail: camilalemke9@gmail.com

Greici MaIA BeHLIng: Doutora em Educação Ambiental pela Universidade Federal do Rio Grande (2018), Mestrado em Educação Ambiental pela Universidade Federal do Rio Grande (2007), Especialização em Direito Ambiental pela Universidade Federal de Pelotas (2011) e Graduação em Ciências Biológicas (Bacharelado e Licenciatura Plena) pela Universidade Federal de Pelotas (2004). Atua como Técnica Administrativa em Educação - Bióloga, da Universidade Federal de Pelotas, desenvolvendo atividades junto ao Núcleo de Reabilitação da Fauna Silvestre e Centro de Triagem de Animais Silvestres da UFPEL. Professora do Curso de Especialização em Educação Ambiental com Ênfase em Espaços Educadores Sustentáveis da UFPEL e colaboradora do Programa de PósGraduação em Ciências Ambientais.

Orcid: https://orcid.org/0000-0001-6086-4028

E-mail: biogre@gmail.com

Francele de Abreu Carlan: Licenciada em Ciências Biológicas pela Universidade Federal de Santa Maria (UFSM), Mestre em Educação em Ciências pela Universidade Federal do Rio Grande do Sul (UFRGS) e Doutora em Educação em Ciências pelo Programa de Pós-Graduação em Educação em Ciências pela (UFSM). Atualmente é professora Adjunta da Universidade Federal de Pelotas (UFPel) e professora permanente do Mestrado em Ensino de Ciências e Matemática da Universidade Federal de Pelotas e professora na especialização em Educação Ambiental - espaços educadores sustentáveis desta mesma instituição.

Orcid: https://orcid.org/0000-0002-1711-9476

E-mail: francelecarlan@smail.com

Este periódico utiliza a licença Creative Commons Attribution 3.0, para periódicos de acesso aberto (Open Archives Initiative - OAI). 